\title{
STANDARD OF FULFILMENT OF REQUIREMENTS IN THE APPLICATION OF TQM IN SLOVAK REPUbLIC
}

\author{
Paulova, I., VAnova, J. \& Doza, P.
}

Abstract: In practise are TQM approaches applied through the EFQM Excellence Model and therefore research is focused on organizations which are applying this model and their level of performance in individual criteria are rated within the National Quality Award of the Slovak Republic. The paper objective is to describe the current state of implementation of human resources management in organizations that participated in National Quality Award of the Slovak Republic. Organizations included in the research have achieved the highest rating and also are applying the EFQM Excellence Model. The model is composed of several areas. In the area of human resources management are important the approaches of implementation of human resources management and subsequent prove of results if the stated strategy is carried out efficiently to the employee satisfaction.

Key words: stakeholders; employees; EFQM Excellence Model; human resources management; strategy
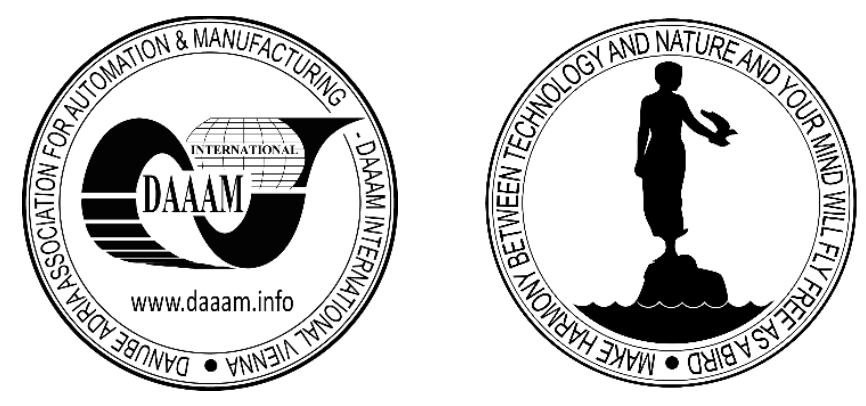

Authors' data: Paulova, I[veta]*; Vanova, J[aromíra]**, Doza, P[eter]***, Slovak University of Technology in Bratislava - Faculty of Material Science and Technology in Trnava", Jana Bottu 25, 91724, Trnava, Slovakia, alena.manova@stuba.sk, jaromira.vanova@stuba.sk,doza.peto@gmail.com

This Publication has to be referred as: Paulova, I[veta]; Vanova, J[aromira] \& Doza, P[eter] (2016). Standard of Fulfilment of Requirements in the Application of Tqm in Slovak Republic, Chapter 38 in DAAAM International Scientific Book 2016, pp.435446, B. Katalinic (Ed.), Published by DAAAM International, ISBN 978-3-902734-099, ISSN 1726-9687, Vienna, Austria

DOI: $10.2507 /$ daaam.scibook.2016.38 


\section{Introduction}

To be special and stand out - this is one of a number of requirements which modern market places on a functioning organizations. If we seek an answer to the question of what constitutes excellence of the organization, certainly we get the following argument: Excellent organizations achieve and keep the highest levels of performance complying or exceeding the expectations of its stakeholders, which undoubtedly included the employees. Many organizations set-up their activities by respecting the ISO 9001 [3]. Today in Europe is used within the ISO 9001 a certified model that is the result of an initiative of representatives of European organizations called EFQM Excellence Model. Essence of the model is composed in 8 concepts of excellence. One of the concepts is "Achieving success" through by competences of employees and is closely follows on the conception "Developing skills" of the organization. ISO certification provide to the organization re-engineering of its processes and also improvement these processes [4].

Quality management system is based on the ISO/TS standard that focuses mainly on processes and on the satisfaction of customers (intermediate or ultimate); and by which both employees and suppliers are involved [7].

The objective of the model is achieving exceptional results by involving all employees to the improvement of the processes, aspiring to efficient management of the whole organization. Therefore a significant key role in such organizations have employees, creating the prerequisites for the successful implementation of objectives of the organization. EFQM Excellence Model identifies the key roles of leadership, policy and strategy, management of human resources and management of partnership and resources that are implement by the going processes to the results. The results are seen from the perspective of different groups called stakeholders - customers, employees and society. The model is built on two key areas of criteria - assumptions and results. The model is divided into 9 criteria, of which are 5 assumptions and 4 results. While assumptions deal with what is carried out and how it is implemented, results evaluated what has been achieved by means of assumptions. Analysis of the results create space for the suggestions of assumptions improvement thus ensuring continuous quality improvement. The maximum number of points that could be achieved is 1000 . Each criterion is evaluated by max. 100 points and criterion 6 (results in relation to customers) a criterion 9 (economic result) are evaluated by 150 points.

\section{Human resources in EFQM Excellence Model}

The exceptional organizations appreciate its employees and create a culture that allows the mutually beneficial fulfillment of organizational objectives and personal objectives. Organizations develop competence of its employees and promote fairness and equality. They care, communicate, reward and recognize in a manner that motivates employees inspires commitment and enables them to use their skills and knowledge to benefit the organization. Exceptional organizations in practice define the knowledge, competencies and level of employee performance required for the achievement of the mission, vision and strategic objectives, efficient production plans, 
developing and retaining talents, develop knowledge and competencies of employees to determine their future employability, motivate employees to engage in improvement and innovation and recognize their efforts and achievements to be involved in the improvement and innovations and recognizes their efforts and achievements.

Employees are the most important asset of the organization. The organization manages, develops and release competences and full potential of its people at an individual level to the level of the entire organization in order to support its strategy, planning and the effective operation of processes. Respect and impartiality, open dialogue, empowerment, appreciation and recognition, care and also ensuring a safe and healthy environment are fundamental to creating commitment and employee participation on the route of organization to excellence. Organization management and management of employees is increasingly being important in a time of change. Improving leadership development, talent management and strategic workforce planning are critical since employees are often the biggest investment in the organization. Effective human resources management and leadership of employees allows the organization to achieve its own strategic objectives and would profit on the strengths of employees and their ability to contribute to the fulfillment of strategic objectives. Successful human resources management and leadership support employee engagement, motivation, development and participation. In the context of total quality management is important to understand that only satisfied employees can bring the organization to the satisfied customers.

Strategic and comprehensive approach to employee management and workplace culture and environment are key part of the strategic planning of the organization. Effective human resources management allows employees to effectively and productively contribute to the overall mission and vision of the organization and achieve the organization objectives. The organization controls its strategic objectives with its own human resources so as to identify, develop, deploy and improve transparently improve taking into consideration the optimal success. Issues such as the organization is able to attract and retain ability of employees to develop and deliver products and services in accordance with the objectives set out in the strategies and action plans, taking into consideration the needs and expectations of customers. This includes regular analysis of the current and future needs of human resources and the development and implementation of human resources management with objective criteria relating to recruitment, career development, support, compensation, valuation and evaluation of managerial functions.

The organization identifies, develops and keeps competences of employees. If the organization creates a structure to allow its employees continuously develop their own competences, assume greater responsibility and show more initiative, after that the employees contribute to the development of the workplace. This can be achieved by that they combine their own performance objectives with the strategic objectives of the organization and also by involving them in the development of policies related to education, motivation and valuing of employees. In practice this assumption may be concentrated in competency strategy that describes the need to develop competences of employees and methods of application (e.g. learning from colleagues, working movement/mobility, other training). 
Employee involvement is to create and environment in that employees have influence on the decisions and actions that affect their work. It involves creating a culture that supports the mission, vision, and values of the organization in practice, for example recognition and appreciation of creativity, good thoughts/ideas, a special effort. The model focuses on the ability of managers/leaders and employees to actively cooperate in the development of the organization, demolish the structures by creating dialogue, scope for creativity, innovation and recommendations for improving of the performance. Employees should be supported in order to fully use their potential. A suitable implementation of human resources policy depends on all leaders and managers of the organization by demonstrating that they care about issues related to employees and their personal benefits and that actively promote a culture of open communication and transparency. The commitment of employees may be achieved by formal forums such as the consulting commission and daily dialogue (e.g. the proposals to improvement). It is also good practice to implement satisfaction surveys and leader's evaluations to get more specific evaluation of work climate and the use of results to implementation of improvement.

\section{Standard of human resources management in organizations applying the EFQM Excellence Model}

Objective of this paper is to highlight the level of achieving requirements in the organizations in Slovak Republic that implement the EFQM Excellence Model and in the National Prize of the Slovak Republic for quality were among best evaluated. Results are presented for the years 2011-2014. Those organizations can be considered as exceptional in Slovakia. To the evaluation of the level of human resources were selected 18 organizations, thereof 16 business subjects and 2 public administrations. In order to assess the level of fulfilment of individual concepts of EFQM Excellence Model, is necessary to identify the level of fulfilment of the all criteria of the model, allocate criteria related to the human resources management (assumption criterion 3 and result criterion 7), as well as the total number of points achieved for the organization as a whole.

Assessed organizations have achieved a score between 403 to 562 points. The average value of 18 organizations has reached 368 points. We present point rated only because certain ratios compared to other criteria, respectively organization as a whole. This paper focuses on monitoring the level of criteria dealing with strategy and human resource management. This area concerns the assumption criterion 3 and result criterion 7. Average rating of evaluated organizations is for assumption criterion 3 employees $-40,01$ points and for result criterion 7 results in relation to employees 30,37 . 


\section{Average number of achieved points in the set \\ of data in criteria 3 and 7}

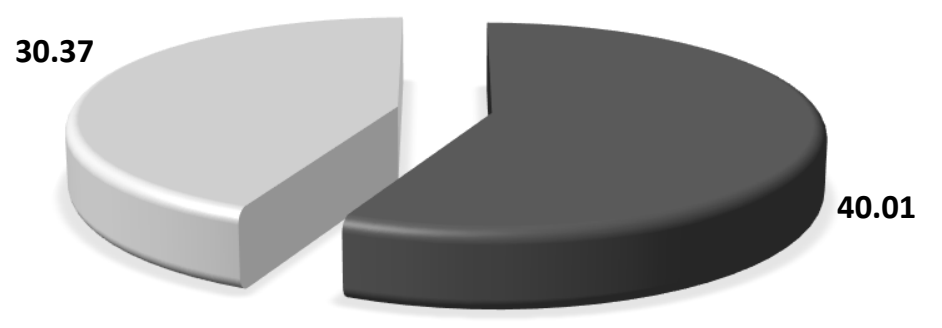

国 3 employees

17 results in relation to employees

Fig. 1. Average number of achieved points in the set of data in criteria 3 and 7

The Fig. 1 shows that the organizations are trying to create good assumptions for human resources management considering to fulfil of the strategy, vision and mission of the organization. From a lower evaluation result criterion is evident that the assumptions are not always adjusted to the satisfaction of the employees, i.e. the perception of employees is less than leaders expect. Simultaneously result criterion indicates the average performance of processes related to human resources management. In terms of process approach to managing human resources it can be concluded that the strength of exceptional companies is planning, fulfilment of plans, but their implementation is not systematically addressed. Improvement of processes related to the human resources management is only in some areas and often does not result from reactions of employee's side.

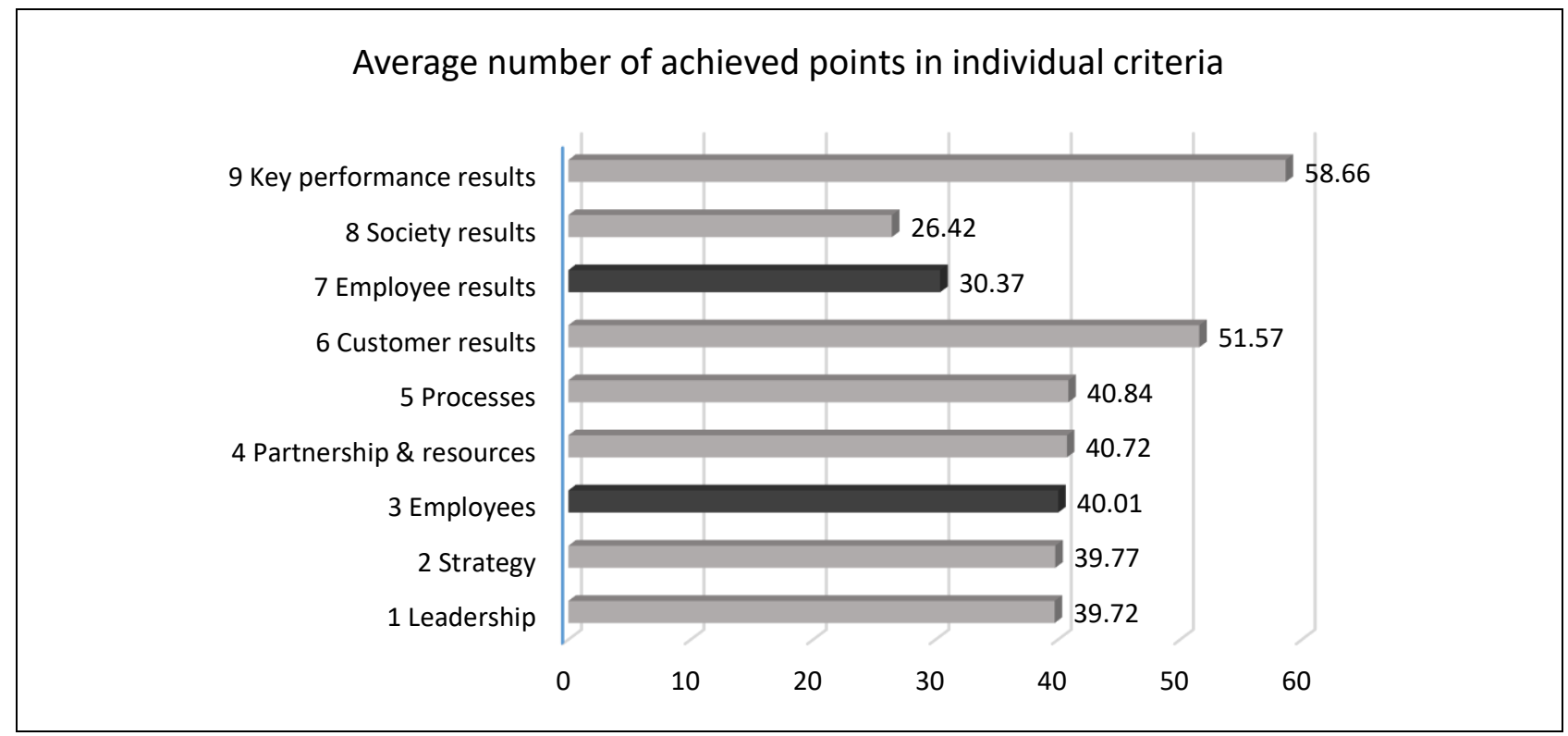

Fig. 2. Average number of achieved points in individual criteria 
The Fig. 2 shows the average values achieved by individual criteria EFQM Excellence Model in the evaluated organizations. On the chart is clearly to see the balance of levels of each assumption criteria. It follows that the organizations have well established conditions to achieving excellence of the organization, so they have a defined strategy, clearly stated the objectives and these objectives are implemented by competent employees. The question is if the strategy of the organization is fulfilling efficiently and to the satisfaction of all stakeholders.

The Fig. 3 below shows us to convert the point evaluation of individual criteria of model to percentage fulfilment. Here we give the conversion due to the comparison of achieving the level of criteria 3 and 7 in individual organizations that had different overall point evaluation.

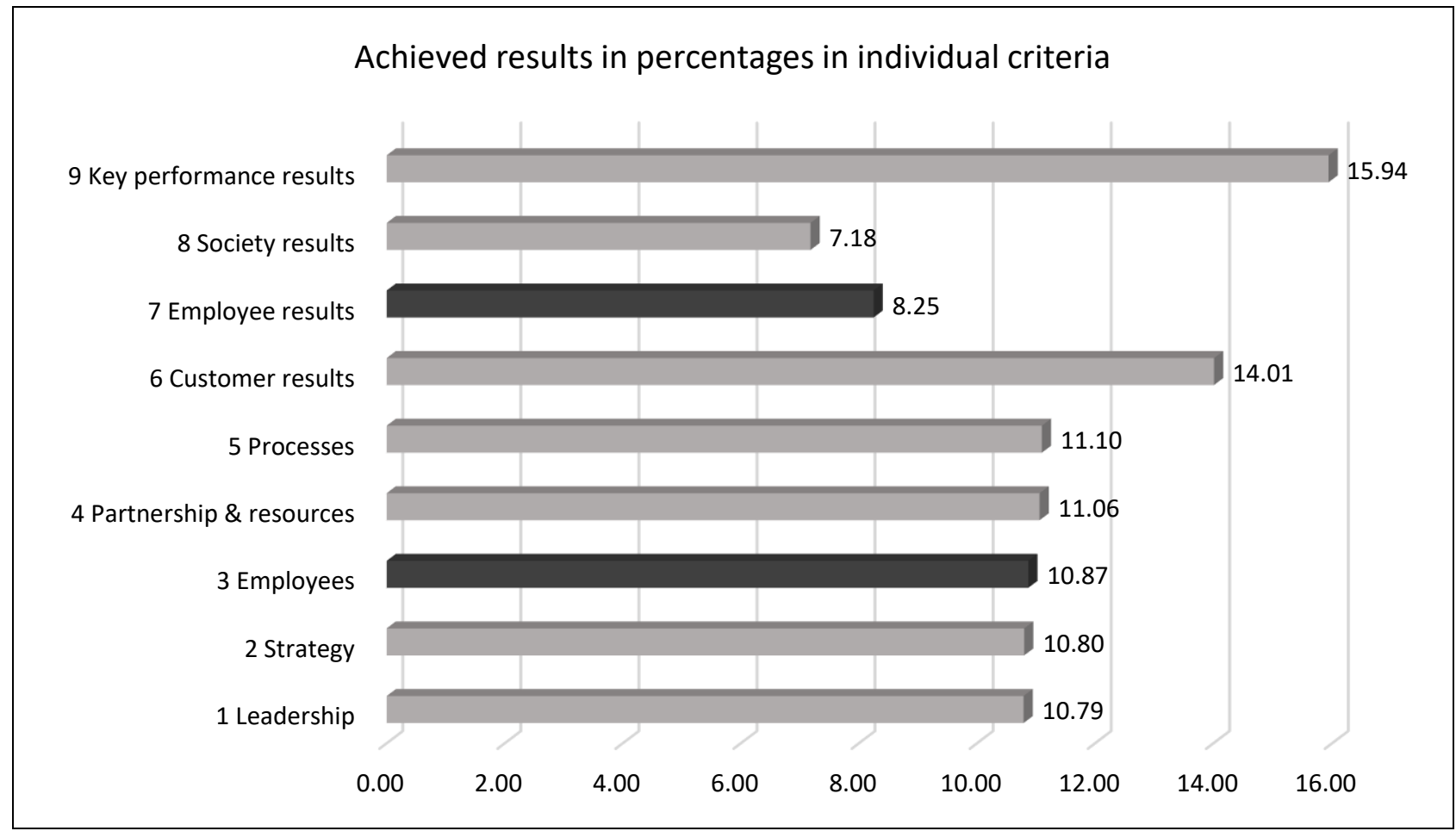

Fig. 3. Achieved results in percentages in individual criteria

In Fig. 4 is summary comparison of the level of achievement of criteria 3 and 7 in individual evaluated organizations. Follows from the above that many organizations, even though it is closer to the concept of an exceptional, they inefficiently manage human resources and employees do not perceive approach management to the employees as a very satisfied. This unflattering approach can be noted in the organizations no. $812,16,17$ and 18. Although in organization is created strategy of human resources management, but that is provided to employees, are not that what just suits them. 
Employees - comparison of assumption and result criteria of the monitored subjects (\% proportion of obtained number of points)

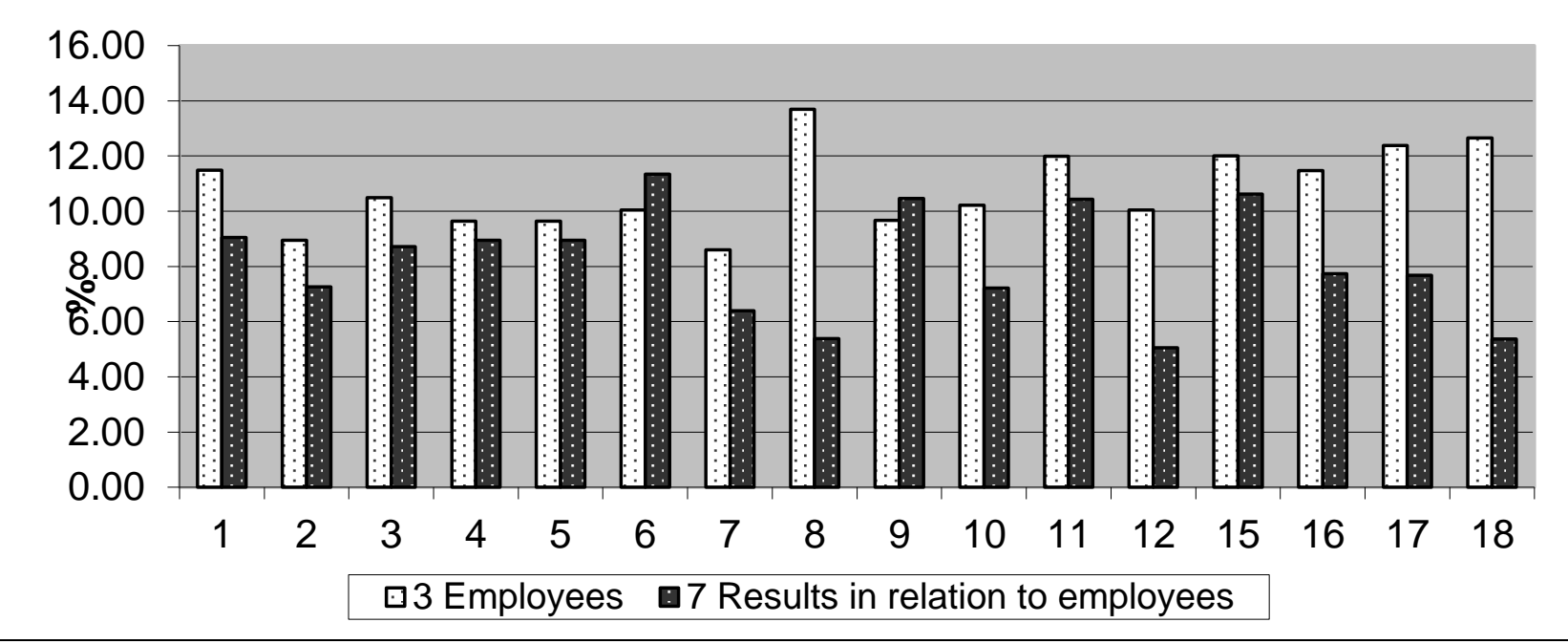

Fig. 4. Comparison of assumption and result criteria in set of data

The percentage expression of achieved points in individual criteria

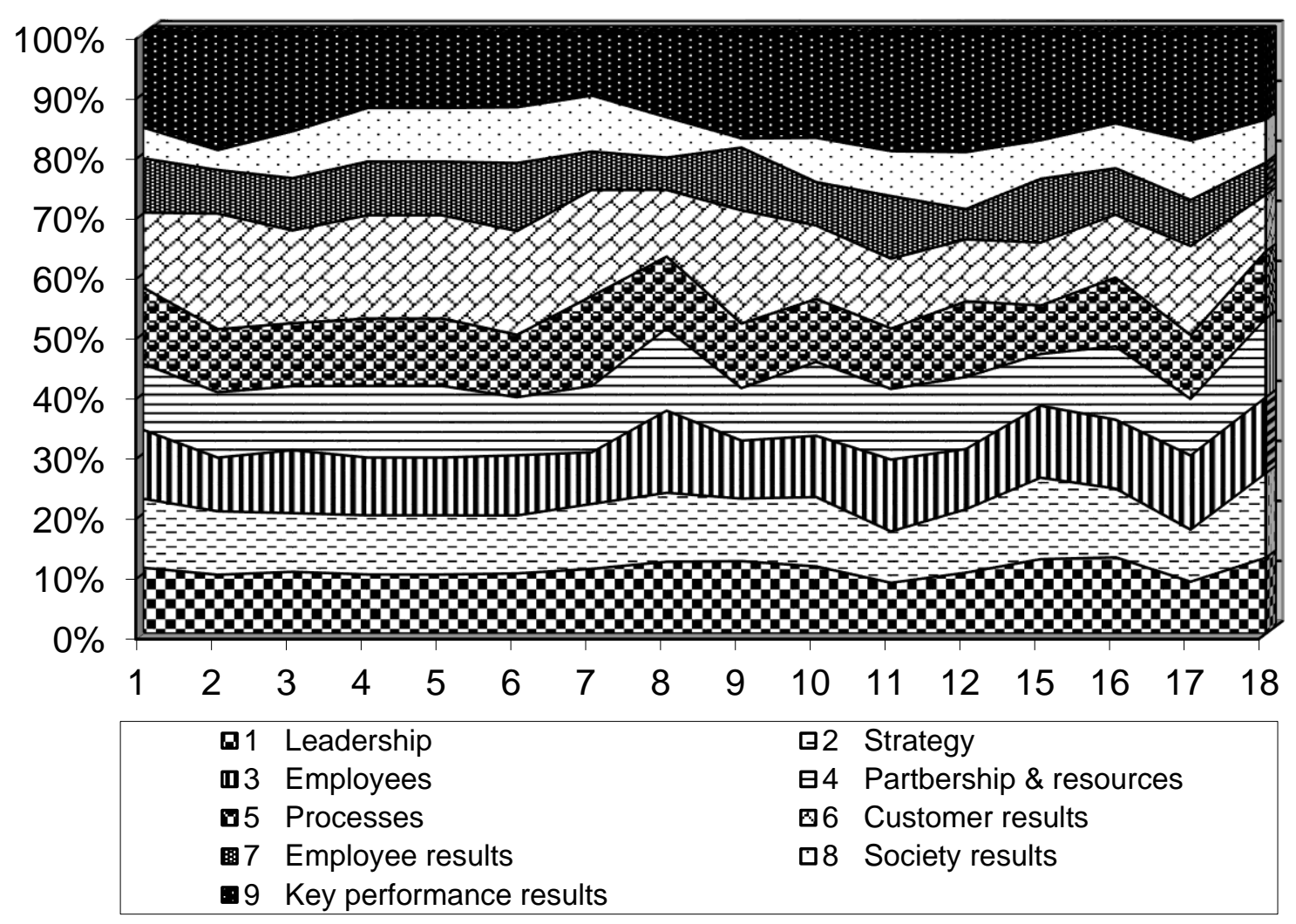

Fig. 5. Percentage expression of the number of achieved points in individual criteria

On the Fig. 5 is possible to compare the individual evaluated organizations in all criteria and its individual proportions of evaluations between the individual criteria. 
Evaluations have been carried out by external evaluators. It also includes the identification of strengths and suggestions to improvement. Below are showed the key and most frequently identified strengths, as well as suggestions to improvement. Suggestions to improvement should be the basis for drawing up called improvement action plan.

\section{Strengths of assumption criterion 3 - employees:}

- Determination of organizational structure linked to the process management.

- The set structure of documents and records in human resources management (internal directives in field of human resources management, database of internal employees, work placement profiles personal employee card, appointment letters, employee evaluation sheets, register of responsibilities and competences).

- Human resources planning.

- The financial and non-financial system of remuneration and pricing, including records.

- The use of tests in selection procedures.

- The use of communication channels (intranet, e-learning).

- Existence of communication strategy creates conditions for the involvement of stakeholders into the development of organization.

- Existence of the concept of integrated communication creates conditions for effective communication of all selected communication channels regard to the target group.

- The use of satisfaction surveys of employees to improve their own approaches to communicate the principles of excellence and development plans of employees.

- Logical scheme of human resources management/activities of HR department.

- Education plan created on basis customer requirements, the organization as a whole and suggestions of superiors.

- Getting the feedback from employees through surveys.

- The development and use of vertical and horizontal communication.

- An extensive variety of communication tools and planning work meetings.

- A stable and transparent remuneration system that follow up on employee performance.

- A wide variety of support tools from the social program.

- An extensive support of social, cultural and sport activities for employees and their families.

- Motivational mechanism of financial and non-financial motivation for submitting implemented "proposal to improve".

- The creation of competency model.

- Respect and compliance with the organization Code of Ethics.

- Introduced system of evaluation and self-evaluations of employees. 
- Mentoring and tutoring of new employees.

- Continuous improvement of the adaptation process of new employees.

- The effort to transferring good practices from abroad through educational trips for employees.

- Development of care plan for employees.

- The moral valuing of employees by management.

- Social, cultural and sport activities for employees and their family members.

\section{Strengths of result criterion 7 - results in relation to employees:}

- The developing activities in area of monitoring perception of employee satisfaction (e.g. satisfaction survey of employees).

- Presented positive results in certain areas, for example increase in the number of employees, stabilized turnover rate, growing trend of survival.

- Regular review of the employee satisfaction set as a standard tool of feedback and evaluation of the appropriateness of the policy tools of HR.

- Improving the results between two organized surveys.

- Linking approaches, the cause and results of surveys as a consequence.

- Existence of objective indicators.

- A significant shift in motivation, information and communication between the years.

- Comprehensive measuring of employee perceptions through an extensive questionnaire.

- Appropriate structuring surveys.

- Suitable expression of results as equity indicators.

- Show a large number of results mostly as positive trend.

- Monitoring education effectiveness.

\section{Proposals to improve the criterion 3}

- A clear definition of the differences in the management of permanent employees and the part-time employees.

- Presentation of solutions of suggestions from employees, alternatively from the black box.

- Presentation of examples of using the feedback in relation to employees (e.g. from audits, meetings, satisfaction surveys, etc.).

- Linking the efficiency, productivity and profitability of work to evaluation of employees.

- Development of e-learning activities of the company in accordance with the communication strategy and HR development strategy.

- Knowledge management as a further potential development of an organization towards excellence - indication in the form of project sharing knowledge, position of manager to knowledge management. 
- Care of employees has a wide scope in that is not entirely clear its connection to the concept of HR management and strategy as such.

- Analysis of communication needs for the development of the communication policy and strategy as part of the strategy of human resource management.

- Existence of a comprehensive strategy of human resources development instead of partial documents.

- Description of mentoring and tutoring for new employees/career development/adaptation process.

- Systemic identification of employee knowledge.

- Description of the authorized members of employees and mechanism of leader substitute to performance and solve activities (the provision of competences).

- Identifying communication needs of employees.

- Designing a comprehensive communication policy/strategy (e.g. internal communication strategy).

- Description of the exchange of experience, knowledge and findings among employees.

- Improving of the use of unit/proportional indicators of performance against cumulative.

- The creation of learning plan based on customer requirements, the organization as a whole and suggestions superiors.

- Linking the training plan to the budge, needs, claims of stakeholders and laws.

- Description of teamwork (vertical and horizontal) and development of team skills.

- A more detailed description of the social agenda and scope of support.

- Performing regular analysis of the needs of human resources.

- Include the terms and conditions of career progression in human resources management and its use to motivate employees.

- Developing a training plan according to employee category and according to type of education (categorized in IP human resources management - A to $\mathrm{H}$ ) and following the personal development plans.

- Showing the managers evaluation by employees.

- Evaluation of employee satisfaction with the level of communication in the organization.

- Evaluation of the effectiveness of resources spent on education (budget/employee/errors).

\section{Proposals to improve the criterion 7:}

- Monitoring of the perception and satisfaction of employees and showing their performance by using the full width of the monitoring possibilities (see description of the model $7 a, 7 b)$. 
- Seeking and finding an appropriate combination of the methods of monitoring with regard to the feasibility of obtaining relevant data and information value.

- Determination of key criteria and indicators for monitoring the results in relation to employees.

- Presentation of own objectives and trends of reported results.

- Define basis performance indicators in the area of human resources and targeted and consistent tracking of these indicators in relation to HR policy.

- Use benchmarking with the best in a similar group or at least with a diameter within the group to most of results (also internal).

- Tracking trends in satisfaction and performance.

- Use a mutual comparisons of development of operational results and planned objectives of ensuring interpretability development trends.

- Seeking for ways of increasing return of filled up questionnaires.

- Propose measures to prevent decline in satisfaction.

- Few of relevant performance indicators in relation to employees.

- Monitoring of performance as remuneration, turnover, innovatory suggestions, absenteeism, use of the social fund, evaluation of the training cost, implementation of the plan of education etc.

- Insufficient range of data in terms of time coverage that do not permit a reliable medium-term trend.

- Planning of the operational objectives to all results.

- Monitoring the level and form of benefits for employees and its regularly reviewed.

\section{Conclusion}

Any organization cannot function without human factor and of course cannot even build any system. Involved, loyal and skilled employees are therefore an essential condition for the success of the organization and its sustainable development.

The total potential of employees can used to benefit of organization through common values, growing mutual trust and facilitating initiatives. It is important that critical organizational objectives and priorities as well as ways and means of its achieving have been accepted by all employees. Communication within the organization should ensure linkages and relationships between organization management, individual departments and employees themselves. Main objective is to engage the entire company in achieving envisaged objectives, strengthen internal integrity of the organization social system and work towards excellence. 
Paulova, I.; Vanova, J. \& Doza, P.: Standard of Fulfilment of Requirements in the ...

\section{References}

Paulová, I. Hekelová, E. Šatanová \& A. Šalgovičová, J. (2008). Metódy zlepšovania efektivnosti a úćinnosti TQM. Vydavatel'stvo STU, 2008.304 s. ISBN 978-80-2272857-7, Bratislava

Základní koncepce excelence. EFQM model 2013. Praha: česká společnost pro jakost, (2013). ISBN 978-90-5236-6111-1.

Paulová, I. (2014). Komplexné manažérstvo kvality. Bratislava. Wolters Kluwer. ISBN 978-80-8168-083-0.

Sivri, S., Hennersdorf, S. \& Krallmann, H. (2016) Enhanced Method for Quality-fit (ISO 9001) Operations within the Automotive Industry, Proceedings of the 26th DAAAM International Symposium, pp.0614-0619

Stefanic, N., oskanovic, N. \& Martincevic-Mikic, S. (2009). Improvement of production by using Kaizen, in B. Katalinic (Eds.), Annals of DAAAM \& Proceedings, pp. $1365-1366$.

Vaňová, J. \& Lestyánszka Škůrková, K. (2013). Commitment and employee performance as a condition for the application of principles of quality management in the industrial enterprises, In: Servqual as instrument of services improvement and resources management, Borkowski, S., Rosak-Szyrocka, J., (Ed.), pp. 38-48, University of Maribor, ISBN 978-961-6562-68-3, Maribor

Vaňová, J. \& Lestyánszka Škůrková, K. (2013). Improving public organizations though self-assesment CAF. In: Improvement's Factors in Eneterprises/Products Development, Borkowski, S., Rosak-Szyrocka, J., (Ed.), pp. 9-18, University of Maribor, ISBN 978-961-6562-73-7, Celje

Goicoechea, I., \& Fenollera, M. (2012). Quality Management in the Automotive Industry, Chapter 51 in DAAAM International Scientific Book, pp. 619-632, B. Katalinic (Ed.), Published by DAAAM International, ISBN 978-3-901509-86-5, ISSN 1726-9687, Vienna, Austria

Vaňová, J. \& Lestyánszka Škůrková, K. (2013). Udržatel’ný úspech podniku v kontexte prístupov manažérstva kvality. In: Kvalita, technológie, diagnostika v technických systémoch, pp. 82-87, Slovenská pol’nohospodárska univerzita v Nitre, ISBN 978-80552-1023-0, Nitra 